\title{
The unseen pandemic: treatment delays and loss to follow-up due to fear of COVID
}

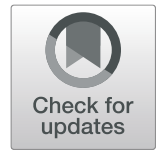

Sharon Einav ${ }^{1}$ and James Tankel ${ }^{2^{*}}$

\begin{abstract}
Background: Fear of contracting SARS-CoV-2 has transformed public interaction with healthcare professionals and hospitals alike. In turn, this has resulted in a collateral impact on patients' health across medical and surgical paradigms. Understanding the causative factors of this fear, and tackling it head on, is vital to return to prepandemic levels of healthcare.

Main body: In this editorial, we explore the evidence base behind the fear of healthcare professionals and facilities that has developed during the course of the SARS-CoV-2pandemic. We also reflect on the ways in which these fears have affected the general public. In so doing, we review a recent article from Montalto et al. that has explored fear of SARS-CoV-2 among patients undergoing surgery in Italy.

Conclusion: While fear of SARS-CoV-2 is uncommon among surgical patients, there are still those who delay or avoiding seeking medical care due to fear of transmission. Physicians must lead the fight against this fear in a hope to regain the trust of the public.
\end{abstract}

Keywords: Viruses, Metal disorders, Infections, Role

Since first being designated a pandemic, nosocomial infection with SARS-CoV-2 has been abundantly described in the medical literature $[1,2]$. With social distancing becoming the norm, avoiding transmission translated into the fear of others as well as the fear for others [3]. This newfound fear affected the perception of healthcare facilities in three ways. Firstly, as hospitals became the battleground on which the fight against SARS-CoV-2 was unfolding, non-essential services were suspended and the public urged to stay away unless necessary. Secondly, the straining of healthcare resources led to preemptive avoidance of healthcare services in an attempt to prevent an additional increase in the overall workload. Finally, hospitals became seen as a place where the risk of SARS-CoV-2 transmission was high. In this editorial, we will discuss the evidence base of the fear that has underpinned these changes and explore the impact that

\footnotetext{
* Correspondence: james.tankel@mail.mcgill.ca

2Division of Thoracic and Upper Gastrointestinal Surgery, Montreal General Hospital - McGill University Health Centre, Montreal, Quebec, Canada Full list of author information is available at the end of the article
}

this has had on the health of the wider public. Finally, we will discuss a recent article that has focused on the fear of SARS-CoV-2 among patients undergoing elective surgery across hospitals in Italy and consider what, as healthcare professionals, must be done to regain the trust of the public.

The perception of healthcare facilities as "high risk" areas has not been entirely misplaced. Pre-vaccination multicenter, observational data $(66,184$ patients) showed that $1.4 \%$ of the patients screened had a positive SARSCoV-2 PCR test. Among these, most were diagnosed during their hospitalization (62.1\%) while a further $10.5 \%$ of these occurred at least 7 days after admission. Exposure to patients with hospital-acquired SARS-CoV2 was associated with a substantial infection risk to other hospitalized patients. For susceptible patients, 1 day in the same ward as someone who was SARS-CoV-2 positive was associated with an additional 7.5 infections per 1000 susceptible patients per day (95\% credible interval 5.5 to $9.5 / 1,000$ susceptible patients/day) [4]. Post vaccination data also suggests that as many as $14 \%$ of

(c) The Author(s). 2022 Open Access This article is licensed under a Creative Commons Attribution 4.0 International License, which permits use, sharing, adaptation, distribution and reproduction in any medium or format, as long as you give

appropriate credit to the original author(s) and the source, provide a link to the Creative Commons licence, and indicate if changes were made. The images or other third party material in this article are included in the article's Creative Commons licence, unless indicated otherwise in a credit line to the material. If material is not included in the article's Creative Commons licence and your intended use is not permitted by statutory regulation or exceeds the permitted use, you will need to obtain permission directly from the copyright holder. To view a copy of this licence, visit http://creativecommons.org/licenses/by/4.0/ 
inpatient infections are nosocomial in origin [5]. Clinical measures and theoretical models have been fervently pursued in an attempt to minimize these perceived risks [6], but the effectiveness of some of these measures is now being questioned.

Patients who become infected during hospitalization may also be more likely to have complications and die. Multicenter data from the first SARS-CoV2 surge showed that adult oncological patients infected during hospitalization were twice as likely to die in hospital as those admitted with community-acquired infection (RR $=2.14,95 \%$ CI 1.76 to 2.61) [7]. More recently, patients with preoperative SARS-CoV-2 infection were shown to have increased rates of post-operative complications [8], respiratory failure, and death [9]. The paucity of data from the post-vaccination era regarding this possibility does little for the ability of the medical community to allay these fears.

Encounters with healthcare workers may also be viewed as a potential risk. In the early stages of the pandemic, both medical and paramedical staff who worked on SARS-CoV-2 wards lived in isolation from their families worldwide. While these measures are no longer considered necessary, by this time, healthcare workers have already experienced personal shunning by the public due to concerns regarding possible SARS-CoV-2 infection [10]. In addition to the fear of the known, the people fear the unknown of SARS-CoV-2 [3]. In fact, an early meta-analysis estimated that the prevalence of SARS-CoV-2 positive samples among those taken from healthcare workers was $11 \%$ (95\% CI 7 to 15$)$ when assessed using reverse transcription-polymerase chain reaction and $7 \%(95 \% \mathrm{CI}: 4,11)$ based on the presence of antibodies. Most healthcare workers with positive screens were working in hospital non-emergency wards during screening (43\%, 95\% CI 28 to 59 ), and $40 \%$ were asymptomatic at the time of diagnosis [11]. Vaccination status likely affects the prevalence of SARS-CoV-2 infection among healthcare workers. Hence, a more recent meta-analysis showed a lower overall pooled prevalence of SARS-CoV-2 among healthcare workers; $3.5 \%$ (95\%CI 1.8-6.6) for studies based on molecular assays, 5.5\% (95\%CI 2.1-14.1) for studies based on serological assays, and $6.5 \%$ (95\% CI 2.5-15.6) for point-of-care capillary blood tests [12]. Needless to say, the fear of SARS-CoV2 transmission has also been significantly propagated by both media and social media.

These public concerns regarding possible SARS-CoV-2 transmission make the study by Montalto et al. ]13[ published in this edition of the Journal of Anesthesia, Analgesia and Critical Care very timely. In their survey of 2376 patients undergoing surgery in 27 Italian hospitals, almost half were concerned they may contract SARS$\mathrm{CoV}-2$ infection during hospitalization or while attending routine checkups in hospital. Patients undergoing surgery in hospitals with a lower surgical volume and with SARS-CoV-2 wards had more concerns regarding possible infection. Having an oncological disease was also independently associated with increased fear of infection. This first publication by the Italian Society of Anestheisa (SIAARTI - Società Italiana di Anestesia ed Analgesia) is a welcome addition to the literature. It highlights the importance of a holistic approach to the care of the patient undergoing surgery. However, no less than this, it also highlights by its very subject matter the added value of anesthesiologists as advocates of the patient.

Concerns regarding SARS-CoV-2 infection have led to cumulative collateral health-related damage. A significant increase in the number of out-of-hospital cardiac arrests has been associated with a decrease in cardiacrelated treatments during the SARS-CoV-2 era [13]. Similarly, treatment delays related to SARS-CoV-2 in patients suffering from acute coronary syndromes have also been associated with an increase in other inhospital major adverse cardiac events [14], lower residual left-ventricular function at the time of hospital discharge and an increase in predicted late cardiovascular mortality [15] .These findings have led to the publication of guidelines reinforcing the need to maintain prepandemic standard of care for both medical [16] and surgical [17] patients.

Montalto et al. surveyed those patients that arrived for surgery. No less interesting would be the data on those patients that never arrived. Surgical treatment delays due to late/non-referral and dropout from postoperative follow-up due to SARS-CoV-2 have thus far been relatively unstudied. In addition, while comorbidity was common in their cohort (prevalence of 54\%), their patients were young relative to other surgical cohorts. Observational studies have shown that those most concerned regarding the possibility of transmission are the elderly and those suffering from psychiatric illnesses [18]. This cohort of patients was under-represented in the associated study.

Prior SARS-COV-2 infection was associated with a lower concern regarding SARS-CoV-2 re-infection during hospitalization [19]. Although reinfection with SARS-CoV-2 may occur, it seems uncommon, usually occurs with a different mutation of the virus [20-22], and is more common among persons that are immune suppressed [23]. Indeed, Current Centers for Disease Control recommendations are not to-quarantine/isolate patients who have recovered from previous SARS-CoV-2 infection if re-exposed to the virus. However, while patients that have survived SARS-CoV-2 infection may feel they have garnered a degree of immunity, the fear and anxiety of re-infection in this specific group of patients is poorly understood. 
Patient anxiety is associated with the pathophysiology of the surgical stress response, potentially influencing wound repair, the immune response, inflammation, and perceptions of pain [24-28]. Montalto et al. identified two major factors associated with a worse perioperative emotional status: a-priori emotional vulnerability and surgery in hospitals with SARS-CoV-2 wards. Family support is a strong mediator for development of resilience in various disease states $[29,30]$. Hence, the concerns expressed by the patients surveyed by Montalto et al. that they would not be able to see family members during hospitalization are highly relevant to the perioperative setting. It is reasonable to be concerned regarding the possibility of detachment from ones support system at the time of greatest need.

What does this study teach us? The SARS-CoV-2 pandemic has exposed many weaknesses in our healthcare systems. In this case, the main lesson is that the healthcare systems must learn to address these very relevant patient concerns. Gone are the days when trust in the treating physician sufficed to allay such fears. Our patients are partially informed and via the internet believe they have access to information previously considered within the professional domain only. The media also ensures that cutting edge data (often with a touch of exaggeration) is available to all. In order to improve medical outcomes, we must learn to listen to the needs our patients express outside of their purely medical care. Quality medical care can only be delivered with open communication and shared decision making.

Future studies should assess the relation between coping, resilience and surgical outcomes in the post- SARS$\mathrm{CoV}-2$ era. More data is required on the epidemiology and clinical implications of in-hospital transmission of SARS-CoV-2 particularly after mass vaccination. Finally, perioperative processes must be streamlined to ensure maximal patient protection during this vulnerable period in their life. Trust must be re-earned. It is imperative that we show our patients we are doing the best we can to earn their trust with regards to protecting them from SARS-CoV-2.

\section{Acknowledgements}

Not applicable

\section{Authors' contributions}

JT-drafting and editing of the manuscript. SE-conceptualization, editing, critical revision. The authors read and approved the final manuscript.

\section{Funding}

No funding was made available for the creation of this manuscript.

\section{Declarations}

Ethics approval and consent to participate

Not applicable

\section{Consent for publication}

Not applicable

\section{Competing interests}

JT received a travel grant of $\$ 4000$ from Medtronic and receives ongoing consultancy payments from Google. SE is a Cochrane editor and editor for Intensive Care Medicine, has received funding for travel, given lectures, owns patents with and/or performed consultancy work for Zoll, Medtronic and Diasorin, and has participated in multicenter trials run by Artisanpharma, Eisai and Astra Zeneca.

\section{Author details}

${ }^{1}$ General Intensive Care Unit of the Shaare Zedek Medical Centre and the Hebrew University Faculty of Medicine, Jerusalem, Israel. ${ }^{2}$ Division of Thoracic and Upper Gastrointestinal Surgery, Montreal General Hospital - McGill University Health Centre, Montreal, Quebec, Canada.

Received: 11 December 2021 Accepted: 26 December 2021

Published online: 28 January 2022

\section{References}

1. Løvestad AH, Jørgensen SB, Handal N, Ambur OH, Aamot HV (2021) Investigation of intra-hospital SARS-CoV-2 transmission using nanopore whole-genome sequencing. J Hosp Infect 111:107-116. https://doi.org/10.1 016/j.jhin.2021.02.022 Epub. PMID: 33647375; PMCID: PMC7908852

2. Meredith LW, Hamilton WL, Warne B, Houldcroft CJ, Hosmillo M, Jahun AS, Curran MD, Parmar S, Caller LG, Caddy SL, Khokhar FA, Yakovleva A, Hall G, Feltwell T, Forrest S, Sridhar S, Weekes MP, Baker S, Brown N, Moore E, Popay A, Roddick I, Reacher M, Gouliouris T, Peacock SJ, Dougan G, Török ME, Goodfellow I (2021) Rapid implementation of SARS-CoV-2 sequencing to investigate cases of health-care associated COVID-19: a prospective genomic surveillance study. Lancet Infect Dis 20(11):1263-1272. https://doi. org/10.1016/S1473-3099(20)30562-4 Epub 2020 Jul 14. Erratum in: Lancet Infect Dis;21(3):e36. Erratum in: Lancet Infect Dis. 2021 Mar;21(3):e36. PMID: 32679081; PMCID: PMC7806511

3. Schimmenti A, Billieux J, Starcevic V. (2020) The four horsemen of fear: an integrated model of understanding fear experiences during the COVID-19 pandemic. Clinical Neuropsychiatry;17 (2): 41-45. https://www.scopus.com/ record/display.uri?eid=2-s2.0-85084043519\&origin=inward\&txGid= 95ddbd8f504cb255da4e3151a8dfba72 Last seen on 6-Dec-2021.

4. Mo Y, Eyre DW, Lumley SF, Walker TM, Shaw RH, O'Donnell D, Butcher L, Jeffery K, Donnelly CA (2021) Oxford COVID infection review team, Cooper BS. Transmission of community- and hospital-acquired SARS-CoV-2 in hospital settings in the UK: A cohort study. PLOS Med 18(10):e1003816. https://doi.org/10.1371/journal.pmed.1003816 PMID: 34637439; PMCID: PMC8509983

5. Lumley SF, Constantinides B, Sanderson N, Rodger G, Street TL, Swann J, Chau KK, O'Donnell D, Warren F, Hoosdally S, OUH Microbiology laboratory; OUH Infection Prevention and Control team, O'Donnell AM, Walker TM, Stoesser NE, Butcher L, Peto TE, Crook DW, Jeffery K, Matthews PC, Eyre DW. (2021) Epidemiological data and genome sequencing reveals that nosocomial transmission of SARS-CoV-2 is underestimated and mostly mediated by a small number of highly infectious individuals. J Infect 83(4): 473-482. https://doi.org/10.1016/j.jinf.2021.07.034 Epub. PMID: 34332019; PMCID: PMC8316632

6. Evans S, Agnew E, Vynnycky E, Stimson J, Bhattacharya A, Rooney C, Warne B, Robotham J (2021) The impact of testing and infection prevention and control strategies on within-hospital transmission dynamics of COVID-19 in English hospitals. Philos Trans R Soc Lond B Biol Sci 376(1829):20200268. https://doi.org/10.1098/rstb.2020.0268 Epub. PMID: 34053255; PMCID: PMC8165586

7. Ponsford MJ, Ward TJC, Stoneham SM, Dallimore CM, Sham D, Osman K, Barry SM, Jolles S, Humphreys IR, Farewell D (2021) A systematic review and meta-analysis of inpatient mortality associated with nosocomial and community COVID-19 exposes the vulnerability of immunosuppressed 
adults. Front Immunol 12:744696. https://doi.org/10.3389/fimmu.2021.744 696 PMID: 34691049; PMCID: PMC8526940

8. Alser O, Kaafarani HMA; COVIDSurg Collaborative. (2021) Outcomes and their state-level variation in patients undergoing surgery with perioperative SARS-CoV-2 infection in the USA: a prospective multicenter study. Ann Surg. https://doi.org/10.1097/SLA.0000000000005310. Epub ahead of print. PMID: 34793350

9. Kiyatkin ME, Levine SP, Kimura A, Linzer RW, Labins JR, Kim Jl, Gurvich A, Gong MN (2021) Increased incidence of post-operative respiratory failure in patients with pre-operative SARS-CoV-2 infection. J Clin Anesth 74:110409. https://doi.org/10.1016/j.jclinane.2021.110409 Epub 2021 Jun 22. PMID: 34225188; PMCID: PMC8216857

10. Cabrini L, Grasselli G, Cecconi M COVID-19 Lombardy ICU Network. (2020) Yesterday heroes, today plague doctors: the dark side of celebration. Intensive Care Med 46(9):1790-1791. https://doi.org/10.1007/s00134-020-061 66-4 Epub. PID: 32613431; PMCID: PMC7328643

11. Gómez-Ochoa SA, Franco OH, Rojas LZ, Raguindin PF, Roa-Díaz ZM, Wyssmann BM, Guevara SLR, Echeverría LE, Glisic M, Muka T (2021) COVID19 in health-care workers: a living systematic review and meta-analysis of prevalence, risk factors, clinical characteristics, and outcomes. Am J Epidemiol 190(1):161-175. https://doi.org/10.1093/aje/kwaa191 Erratum in: Am J Epidemiol. 2021 Jan 4;190(1):187. PMID: 32870978; PMCID: PMC7499478

12. Riccò M, Gualerzi G, Ranzieri S, Peruzzi S, Valente M, Marchesi F, Bragazzi NL, Signorelli C (2021) Occurrence of SARS-CoV-2 infection among healthcare personnel: results from an early systematic review and meta-analysis. Acta Biomed 92(5):e2021311. https://doi.org/10.23750/abm.v92i5.10438 PMID: 34 738585

13. Sun C, Dyer S, Salvia J, Segal L, Levi R (2021) Worse Cardiac Arrest Outcomes During The COVID-19 Pandemic In Boston Can Be Attributed To Patient Reluctance To Seek Care. Health Aff (Millwood) 40(6):886-895. https://doi.org/1 0.1377/hlthaff.2021.00250 Epub 2021 May 26. PMID: 34038193

14. Primessnig U, Pieske BM, Sherif M (2020) Increased mortality and worse cardiac outcome of acute myocardial infarction during the early COVID-19 pandemic. ESC Heart Fail 8(1):333-343. https://doi.org/10.1002/ehf2.13075 Epub. PMID: 33283476; PMCID: PMC7835606

15. Secco GG, Zocchi C, Parisi R, Roveta A, Mirabella F, Vercellino M, Pistis $G$, Reale M, Maggio S, Audo A, Kozel D, Centini G, Maconi A, Di Mario C (2020) Decrease and delay in hospitalization for acute coronary syndromes during the 2020 SARS-CoV-2 pandemic. Can J Cardiol 36(7):1152-1155. https://doi. org/10.1016/j.cjca.2020.05.023 Epub. PMID: 32447060; PMCID: PMC7242185

16. Mahmud E, Dauerman HL, FGP W, Messenger JC, Rao SV, Grines C, Mattu A, Kirtane AJ, Jauhar R, Meraj P, Rokos IC, Rumsfeld JS, Henry TD (2020) Management of acute myocardial infarction during the COVID-19 pandemic: A Consensus Statement from the Society for Cardiovascular Angiography and Interventions (SCAl), the American College of Cardiology (ACC), and the American College of Emergency Physicians (ACEP). Catheter Cardiovasc Interv 96(2):336-345. https://doi.org/10.1002/ccd.28946 Epub. PMID: 32311816

17. Merchant J, Lindsey I, James D, Symons N, Boyce S, Jones O, George B, Cunningham C (2021) Maintaining standards in colorectal cancer surgery during the global pandemic: a cohort study. World J Surg 45(3):655-661. https://doi.org/10.1007/s00268-020-05928-x Epub. PMID: 33423099; PMCID: PMC7796814

18. Midorikawa H, Aiba M, Lebowitz A, Taguchi T, Shiratori Y, Ogawa T, Takahashi A, Takahashi S, Nemoto K, Arai T, Tachikawa H (2021) Confirming validity of the Fear of COVID-19 Scale in Japanese with a nationwide largescale sample. PLoS ONE 202116(2). https://doi.org/10.1371/journal. pone.0246840 PMID 33566868. PMCID: PMC7875410

19. Montalto F, Ippolito M, Noto A, Madotto F, Gelardi F, Savatteri P, Giarratano A Cortegiani A \& the SIAARTI Study Group (2021) Emotional status and fear in patients scheduled for elective surgery during COVID-19 pandemic: a nationwide cross-sectional survey (COVID-SURGERY). Journal of Anesthesia, Analgesia and Critical Care 1(1):17. https://doi.org/10.1186/s44158-021$00022-7$

20. Harrington D, Kele B, Pereira S, Couto-Parada X, Riddell A, Forbes S, Dobbie H, Cutino-Moguel T (2021) Confirmed reinfection with severe acute respiratory syndrome coronavirus 2 (SARS-CoV-2) variant VOC-202012/01. Clin Infect Dis 73(10):1946-1947. https://doi.org/10.1093/cid/ciab014 PMID: 33421056; PMCID: PMC7929017
21. Zucman N, Uhel F, Descamps D, Roux D, Ricard JD (2021) Severe reinfection with south african severe acute respiratory syndrome coronavirus 2 (SARSCoV-2) variant 501Y.V2. Clin Infect Dis 73(10):1945-1946. https://doi.org/10.1 093/cid/ciab129 PMID: 33566076; PMCID: PMC7929064

22. Nonaka CKV, Franco MM, Gräf T, de Lorenzo Barcia CA, de Ávila Mendonça RN, de Sousa KAF, Neiva LMC, Fosenca V, Mendes AVA, de Aguiar RS, Giovanetti M, de Freitas Souza BS (2021) Genomic evidence of SARS-CoV-2 reinfection involving E484K spike mutation, Brazil. Emerg Infect Dis 27(5): 1522-1524. https://doi.org/10.3201/eid2705.210191 Epub 2021 Feb 19. PMID: 33605869; PMCID: PMC8084516

23. Slezak J, Bruxvoort K, Fischer H, Broder B, Ackerson B, Tartof S (2021) Rate and severity of suspected SARS-Cov2 reinfection in a cohort of PCR-positive COVID-19 patients. Clin Microbiol Infect S1198-743X(21):00422-00425. https://doi.org/10.1016/j.cmi.2021.07.030 Epub ahead of print. PMID: 34419576; PMCID: PMC8373524

24. Nelson EA, Dowsey MM, Knowles SR, Castle DJ, Salzberg MR, Monshat K, Dunin AJ, Choong PF (2013) (2013) Systematic review of the efficacy of presurgical mind-body based therapies on post-operative outcome measures. Complement Ther Med. 21(6):697-711. https://doi.org/10.1016/j.ctim.2013. 08.020 Epub. PMID: 24280480

25. Arpino L, lavarone A, Parlato C, Moraci A (2004) Prognostic role of depression after lumbar disc surgery. Neurol Sci 25(3):145-147. https://doi. org/10.1007/s10072-004-0248-x PMID: 15300462

26. Granot M, Ferber SG (2005) The roles of pain catastrophizing and anxiety in the prediction of postoperative pain intensity: a prospective study. Clin J Pain 21(5):439-445. https://doi.org/10.1097/01.ajp.0000135236.12705.2d PMID: 16093750

27. Walburn J, Vedhara K, Hankins M, Rixon L, Weinman J (2009) Psychological stress and wound healing in humans: a systematic review and metaanalysis. J Psychosom Res 67(3):253-271. https://doi.org/10.1016/j. jpsychores.2009.04.002 Epub 2009 Jul 2. PMID: 19686881

28. Villa G, Lanini I, Amass T, Bocciero V, Scirè Calabrisotto C, Chelazzi C, Romagnoli S, De Gaudio AR, Lauro GR (2020) Effects of psychological interventions on anxiety and pain in patients undergoing major elective abdominal surgery: a systematic review. Perioper Med (Lond) 9(1):38. https://doi.org/10.1186/s13741-020-00169-x PMID: 33292558; PMCID: PMC7722323

29. Kukihara H, Yamawaki N, Ando M, Nishio M, Kimura H, Tamura Y (2020) The mediating effect of resilience between family functioning and mental wellbeing in hemodialysis patients in Japan: a cross-sectional design. Health Qual Life Outcome 18(1):233. https://doi.org/10.1186/s12955-020-01486-x PMID: 32680519; PMCID: PMC7367268

30. Bahremand M, Rai A, Alikhani M, Mohammadi S, Shahebrahimi K, Janjani P (2014) Relationship between family functioning and mental health considering the mediating role of resiliency in type 2 diabetes mellitus patients. Glob J Health Sci 7(3):254-259. https://doi.org/10.5539/gjhs.V7n3p2 54 PMID: 25948449; PMCID: PMC4802084

\section{Publisher's Note}

Springer Nature remains neutral with regard to jurisdictional claims in published maps and institutional affiliations.

Ready to submit your research? Choose BMC and benefit from:

- fast, convenient online submission

- thorough peer review by experienced researchers in your field

- rapid publication on acceptance

- support for research data, including large and complex data types

- gold Open Access which fosters wider collaboration and increased citations

- maximum visibility for your research: over $100 \mathrm{M}$ website views per year

At $\mathrm{BMC}$, research is always in progress.

Learn more biomedcentral.com/submission 